\title{
Structural Organization of a Hypermethylated Nuclear DNA Component in Physarum polycephalum
}

\author{
By OLIVER P. PEOPLES, PAUL A. WHITTAKER, DOUGLAS PEARSTON \\ AND NORMAN HARDMAN* \\ Department of Biochemistry, University of Aberdeen, Marischal College, Aberdeen AB9 IAS, \\ Scotland, UK
}

(Received 29 June 1984; revised 13 December 1984)

\begin{abstract}
Digestion of Physarum polycephalum nuclear DNA using the restriction endonuclease HpaII generates two components, distinguishable on the basis of their molecular size. The highmolecular-weight, HpaII-resistant component, which accounts for $20 \%$ of the DNA, contains a fivefold greater concentration of 5-methylcytosine residues than the low-molecular-weight HpalI-digested fraction. Segments of hypermethylated $\left(\mathrm{M}^{+}\right)$DNA are largely composed of a single, long, highly repeated sequence, and this major element is sometimes associated with other less highly repetitive sequences in the $\mathrm{M}^{+}$DNA fraction. Restriction mapping of cloned Physarum $\mathrm{M}^{+}$DNA segments, and Southern blot analysis of genomic DNA using subcloned segments of $\mathrm{M}^{+}$DNA as a probe, provide evidence for sequence variation within different copies of the dominant highly repeated element, and possibly the other associated repeats in $\mathbf{M}^{+}$ DNA, and additionally that almost complete tandemly repeated copies of the major repeat are found in some $\mathbf{M}^{+}$DNA segments.
\end{abstract}

\section{INTRODUCTION}

5-Methylcytosine (5-meC) is the only known naturally-occurring modified base in DNA from higher eukaryotes. 6-Methyladenine is additionally found in the DNA of some, but not all, lower eukaryotic species. Using traditional methods of analysis, 5-meC was shown to be the only modified base in DNA from Chlorella (Bayen \& Dalmon, 1976), Saccharomyces (Hattman et al., 1978) and Physarum (Evans et al., 1973). Methylation has been implicated in various aspects of eukaryotic DNA function, but most recently attention has been focused on its possible role in the regulation of genetic expression (Mavilio et al., 1983). Studies of the distribution of 5-meC in eukaryotic DNA and the nature of methylated sequences might be expected to provide clues as to its possible functions.

Nuclear DNA in sea urchin (Bird et al., 1979) and Physarum polycephalum (Whittaker \& Hardman, 1980) contains a clearly distinguishable 'compartment' which resists digestion using the methylation-sensitive restriction endonuclease HpalI. In Physarum, this component represents $20 \%$ of the nuclear DNA, and it comprises DNA segments $20-40 \mathrm{~kb}$ long which contain contiguously methylated MspI restriction sites (Whittaker \& Hardman, 1980). The HpaII-resistant DNA fraction can be isolated by sucrose gradient centrifugation (Whittaker $e t$ al., 1981). This offers a means to analyse the component biochemically in order to determine the content of 5-meC in HpaII-resistant DNA and to identify specific nucleotide sequences associated with it. Previous studies led to the identification of a major repetitive DNA sequence which is confined to the HpaII-resistant fraction of the Physarum genome (Whittaker et al., 1981 ; Peoples \& Hardman, 1983). The present work was concerned with the base composition analysis of the HpaII-resistant compartment of Physarum DNA, and the identification of further repetitive sequence families which are associated with this DNA fraction.

Abbreviation: 5-meC, 5-methylcytosine. 


\section{METHODS}

Sources of DNA. Nuclear DNA was isolated as described previously (Hardman et al., 1979) from Physarum polycephalum strain LU648 $\times$ LU688 (Cooke \& Dee, 1975) a generous gift from Dr Jennifer Dee, Department of Genetics, University of Leicester, UK.

Physarum recombinant plasmid DNA clones pPH29 and pPH53 (McLachlan \& Hardman, 1982) contain BamHI/HindIII segments of Physarum nuclear DNA inserted into the vector pBR322. Subcloning of pPH53 generated pPH53a and pPH53b (Peoples et al., 1983) referred to in this study. The PL series of Physarum genomic DNA clones were constructed as described previously (Whittaker, 1982; Peoples et al., 1983).

Base composition analysis of DNA. Samples of DNA $(50 \mu \mathrm{g})$ were dissolved in $0 \cdot 1 \mathrm{ml} 1 \mathrm{mM}-\mathrm{MgCl}_{2} / 10 \mathrm{mM}$-Tris$\mathrm{HCl} \mathrm{pH} \mathrm{8.0,} \mathrm{and} \mathrm{digested} \mathrm{using} 0.15 \mathrm{mg} \mathrm{DNAase} \mathrm{I} \mathrm{for} 1 \mathrm{~h}$ at $37^{\circ} \mathrm{C}$. Then $0.02 \mathrm{ml} 1 \mathrm{M}$-Tris/ $\mathrm{HCl} \mathrm{pH} \mathrm{9.5} \mathrm{was} \mathrm{added}$ followed by 0.05 units of Crotalus durissus phosphodiesterase, and the incubation was continued for $1 \mathrm{~h}$. Finally, 2 units of calf intestinal alkaline phosphatase were added and incubation continued for a further $4 \mathrm{~h}$. Enzymes were removed by overnight precipitation at $-20^{\circ} \mathrm{C}$ in the presence of 2 vols ethanol, followed by centrifugation for $15 \mathrm{~min}$ in an Eppendorf microcentrifuge. Nucleosides were recovered from supernatants by evaporating to dryness.

For HPLC analysis, approximately $10 \mu \mathrm{g}$ nucleosides were dissolved in $50 \mu \mathrm{l}$ distilled water and injected into a chromatography column containing micro-Bondapak $\mathrm{C} 18$ reversed phase silica gel charged with octadecyl groups. The column was equilibrated with a solution of $0.1 \%$ phosphoric acid, previously filtered through a $0.45 \mu \mathrm{M}$ Millipore filter and degassed with helium immediately before use. Nucleosides from test samples were identified by comparison with elution profiles of authentic compounds. The relative abundance of nucleosides was determined from areas under the peaks in the elution profile.

DNA blotting, hybridization and restriction mapping procedures. Routine experimental methods, including plasmid DNA isolation, gel electrophoresis, nick-translation of DNA probes and sub-cloning of DNA fragments, were based on procedures described previously (Hardman et al., 1979; Whittaker et al., 1981; Peoples \& Hardman, 1983).

The 'sandwich blot' method (Smith \& Summers, 1980), based on the Southern blot technique (Southern, 1975), was used to generate replicate filters for hybridization with different DNA probes. Hybridization was done under conditions described previously (Peoples et al., 1983). Autoradiograms were developed using Fuji-Rx X-ray film.

\section{RESULTS}

\section{Isolated HpaII-resistant Physarum DNA is enriched in 5-meC residues}

Physarum nuclear DNA, uniformly labelled by growth of microplasmodia in the presence of deoxy $\left[5-{ }^{3} \mathrm{H}\right]$ adenosine, was terminally-digested using the restriction nucleases $\mathrm{HpaII}$ and HhaI, and subsequently fractionated by sucrose gradient centrifugation, as described previously (Whittaker et al., 1981). Digestion with a combination of HpaII/HhaI increases the resolution between the digested and undigested fractions, which are referred to as ' $\mathbf{M}^{-}$' and ' $\mathbf{M}^{+}$', respectively (Whittaker \& Hardman, 1980). Purified DNA from each fraction was subjected to base composition analysis by HPLC after complete enzymic digestion to nucleosides. Results of the analysis are shown in Table 1 . The results show that the mean $\mathrm{mol} \% \mathrm{G}+\mathrm{C}$ content of the $\mathbf{M}^{+}$fraction is similar to that of $\mathbf{M}^{-}$or total DNA, whereas the proportion of 5-meC residues in

\section{Table 1. Base composition analysis of Physarum DNA}

Total Physarum nuclear DNA $(10 \mu \mathrm{g})$ was digested to nucleosides using DNase $\mathrm{I} / \mathrm{snake}$ venom phosphodiesterase/alkaline phosphatase, and subjected to HPLC analysis as described in the text. Peak assignments were made with reference to elution times of authentic compounds. Recoveries were estimated from peak areas using both the method of internal standards and the method of external standards. The data are means \pm SD of five determinations on two different samples of each DNA fraction.

\begin{tabular}{|c|c|c|c|c|c|c|}
\hline \multirow[b]{2}{*}{ Sample } & \multicolumn{5}{|c|}{ Mean percentage composition } & $\mathrm{meC}$ \\
\hline & $\mathrm{C}$ & $\mathrm{meC}$ & A & G & $\mathrm{T}$ & $\mathrm{C}+\mathrm{meC}$ \\
\hline Total DNA & $20.92 \pm 0.33$ & $1.57 \pm 0.48$ & $28.94 \pm 1.92$ & $20 \cdot 52 \pm 0 \cdot 49$ & $27 \cdot 27 \pm 0.58$ & 6.98 \\
\hline $\mathrm{M}^{+}$DNA & $20 \cdot 61 \pm 0 \cdot 16$ & $416 \pm 0.41$ & $27 \cdot 37 \pm 0 \cdot 70$ & $20 \cdot 41 \pm 0.30$ & $27 \cdot 44 \pm 0.42$ & $16 \cdot 75$ \\
\hline $\mathrm{M}^{-}$DNA & $20 \cdot 84 \pm 0 \cdot 22$ & $0.69 \pm 0.15$ & $30 \cdot 88 \pm 1 \cdot 26$ & $20 \cdot 40 \pm 0.40$ & $27 \cdot 18 \pm 0.68$ & $3 \cdot 20$ \\
\hline
\end{tabular}




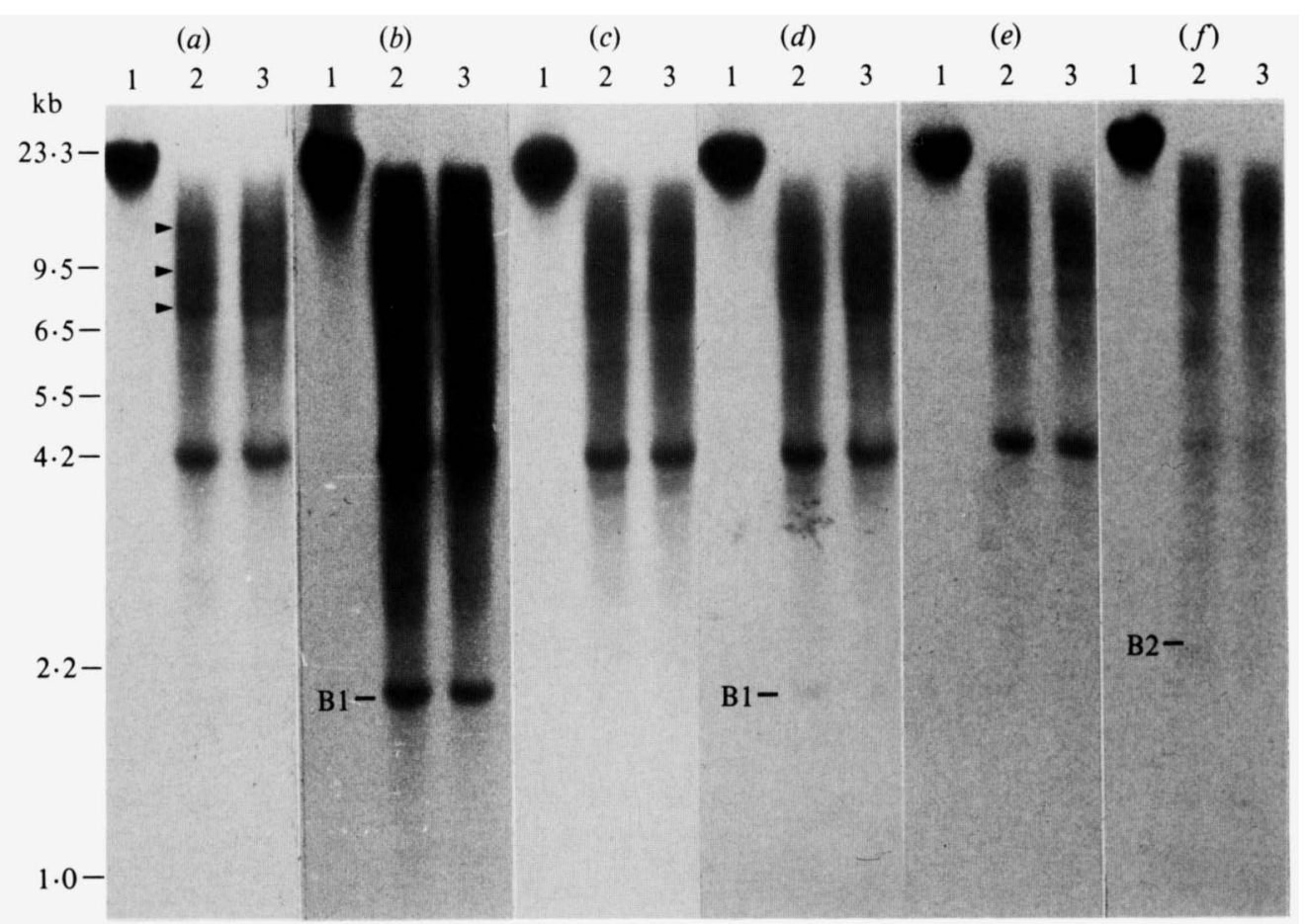

Fig. 1. Hybridization of recombinant phage DNAs to restriction digests of Physarum nuclear DNA. Samples of Physarum nuclear DNA, digested using (1) HpaII, (2) HpaII + MspI, or (3) MspI, were electrophoresed on $0.75 \%$ agarose gels, blotted on to nitrocellulose and probed with nick-translated probes of: (a) PL-3; (b) PL-5; $(c)$ PL-12; (d) PL-13; (e) PL-15; and $(f)$ PL-16. Specific activities of probes were $1 \times 10^{7}-5 \times 10^{7}$ c.p.m. $(\mu \mathrm{g} \mathrm{DNA})^{-1}$. Filters were exposed to X-ray film overnight at $-50{ }^{\circ} \mathrm{C}$. Arrowheads in $(a)$ indicate the positions of faint high-molecular-weight DNA bands showing homology with each probe. $\mathrm{B} 1$ and $\mathrm{B} 2$ indicate positions of $2.0 \mathrm{~kb}$ and $2.2 \mathrm{~kb}$ bands respectively [faint in $(d)$ and $(f)]$.

$\mathbf{M}^{+}$DNA is approximately fivefold greater than the $\mathbf{M}^{-}$fraction. It is concluded that the $\mathbf{M}^{+}$ fraction is hypermethylated; although the compartment contains only $20 \%$ of the DNA (Whittaker \& Hardman, 1980), it contains about two-thirds of all the 5-meC in the genome.

\section{Identification of sequences located in cloned $\mathrm{M}^{+}$DNA segments}

The construction of a clone bank of Physarum nuclear DNA, using the bacteriophage vector $\lambda-1059$, has been described previously (Whittaker, 1982; Peoples \& Hardman, 1983). The library contains Physarum DNA inserts about $10-15 \mathrm{~kb}$ in length. Cloned segments of $\mathbf{M}^{+}$DNA were identified by Benton-Davis hybridization screening (Benton \& Davis, 1977) using nonhomologous cloned Physarum DNA probes specific for the $\mathbf{M}^{+}$fraction (pPH29 and pPH53; Whittaker et al., 1981). It was thus concluded that the repetitive elements present in the clones pPH29 and pPH53 were closely linked in virtually all cloned segments of $\mathbf{M}^{+}$DNA, and a collection of six cloned $\mathrm{M}^{+}$-specific DNA segments was selected for further study (PL-5, 6, 12, 13, 15 and 16). A long, major repetitive element, the $\mathrm{HpaII-repeat,} \mathrm{has} \mathrm{already} \mathrm{been} \mathrm{identified} \mathrm{in}$ these DNA clones (Peoples \& Hardman, 1983).

In order to identify repeated DNA sequences in these segments other than those displaying homology with pPH29 and pPH53, DNA from each recombinant phage was isolated, nicktranslated and used to probe Southern blots of Physarum genomic DNA digested using HpaII, MspI or HpaII + MspI (Fig. 1). In all cases, the probes detected high-molecular-weight fragments in $\mathrm{HpaII}$ digests, typical of $\mathrm{M}^{+}$-specific DNA sequences, thus confirming their origin (lanes 1). In contrast the sequences were digested with the isoschizomer MspI (lanes 2 and 3), 
(a) $\mathrm{pPH} 29$ probe

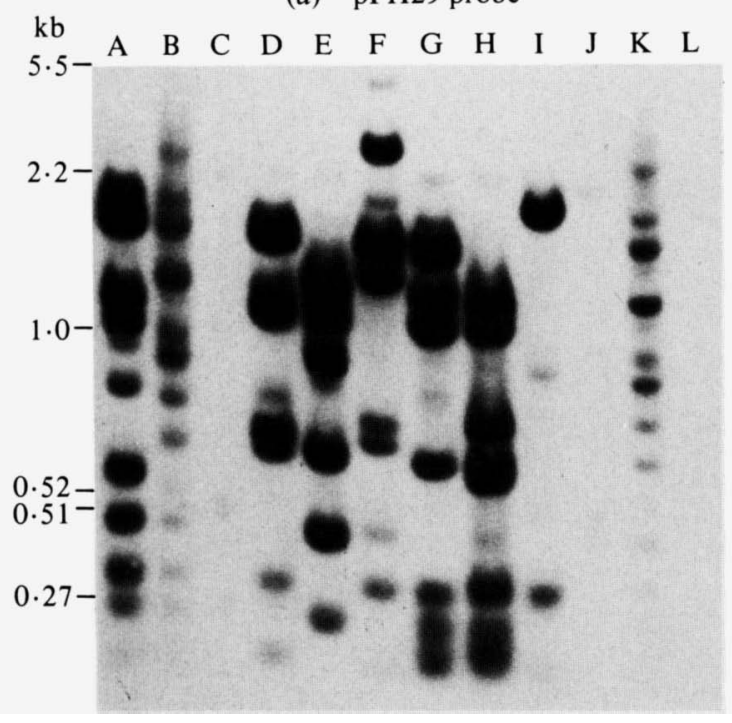

(b) $\mathrm{pPH} 53$ probe

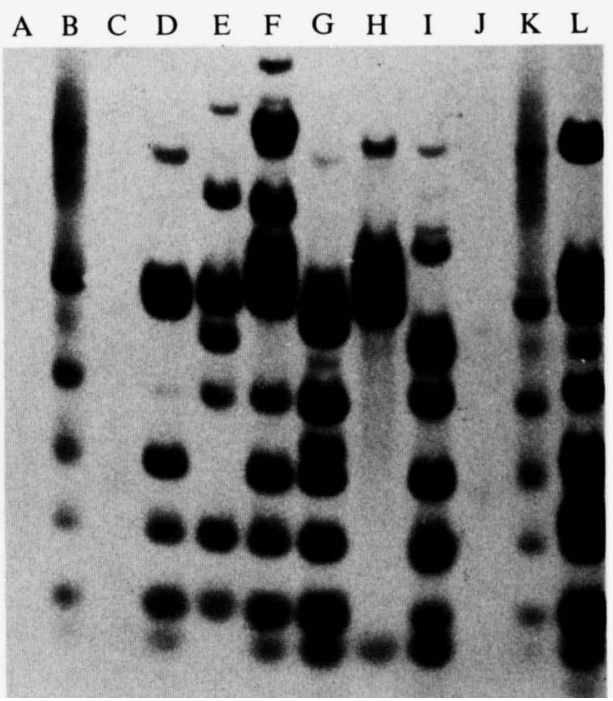

Fig. 2. Hybridization of pPH29 and pPH53 probes to Sau3AI digests of Physarum genomic DNA. Various DNA samples were restricted using Sau3AI, separated on $1.5 \%$ agarose gels, and duplicate nitrocellulose blots prepared using the 'sandwich blot' method. Filters were probed using $(a)$ pPH29 DNA, or $(b)$ pPH53 DNA. All lanes contained $1 \mu \mathrm{g}$ DNA with the exception of lanes A and $\mathrm{L}$ which contained $0.1 \mu \mathrm{g}$ of isolated pPH29 and pPH53 Physarum DNA inserts, respectively. Lanes C and J contained HindIII restriction fragments of ${ }^{32} \mathrm{P}$-labelled PM2 as size markers. Hybridization conditions and autoradiography were as described previously (Peoples \& Hardman, 1983). A, pPH29 insert DNA; B, K, Physarum genomic DNA; C, J, marker DNA fragments; D, PL-3 DNA; E, PL-5 DNA; F, PL-12 DNA; G, PL-13 DNA; H, PL-15 DNA; I, PL-16 DNA; L, pPH53 insert DNA.

which cleaves both the unmethylated sequence $\mathrm{CpCpGpGp}$ and the methylated analogue CpmeCpGpGp. Only one major band of hybridization was detected in all the MspI digests, corresponding to DNA fragments in genomic DNA with a uniform length of $4.3 \mathrm{~kb}$. This signal, and the faint bands of hybridization of high-molecular-weight (arrows, Fig. 1), probably arise from the presence of highly-repeated pPH29/pPH53-homologous sequences with a uniform arrangement of MspI (HpaII) restriction sites, referred to as the HpaII-repeat (Peoples \& Hardman, 1983); similar DNA bands can be seen in ethidium bromide-stained agarose gels of MspI-digested Physarum DNA (Whittaker \& Hardman, 1980), supporting the idea that they are derived from highly repetitive elements in Physarum DNA. Additional, fainter bands of hybridization were detected at $2.0 \mathrm{~kb}$ using PL-5 and PL-13 (B1), and at $2.2 \mathrm{~kb}$ using PL-16 (B2). These signals result from the presence in the clones of additional sequences unrelated to the HpalI-repeat, since the bands are not detected when similar restriction digests of genomic DNA are probed using pPH29 or pPH53 DNA (Peoples \& Hardman, 1983).

\section{HpaII-repeats located in cloned $M^{+}$DNA segments have a common internal structure}

In order to demonstrate that cloned copies of the repeated elements derived from $\mathrm{M}^{+}$DNA have a structure similar to those in Physarum genomic DNA, duplicate filters of Sau3AIdigested DNA samples were probed using nick-translated insert DNA fragments recovered from pPH29 or pPH53. The lack of cross-homology of pPH29 and pPH53 insert DNA sequences (Fig. $2 a$, lane $\mathrm{L}$, and Fig. $2 b$, lane A) confirms the purity of the probes, and is in accord with previous work suggesting that they are derived from different portions of the HpaIIrepeat (Peoples \& Hardman, 1983). Hybridization signals to genomic DNA tracks (lanes B and K) were very similar to the 'average' pattern deduced for the cloned $\mathrm{M}^{+}$DNA sequences PL-3, 5, $12,13,15$ and 16 (lanes D-I), indicating that the cloned copies of these repeated elements are 
(a)

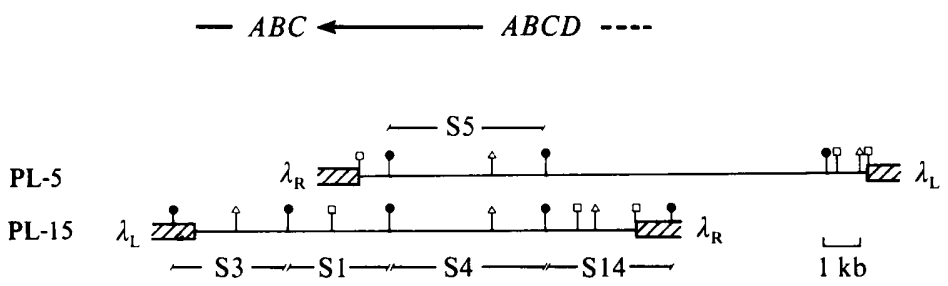

(b)

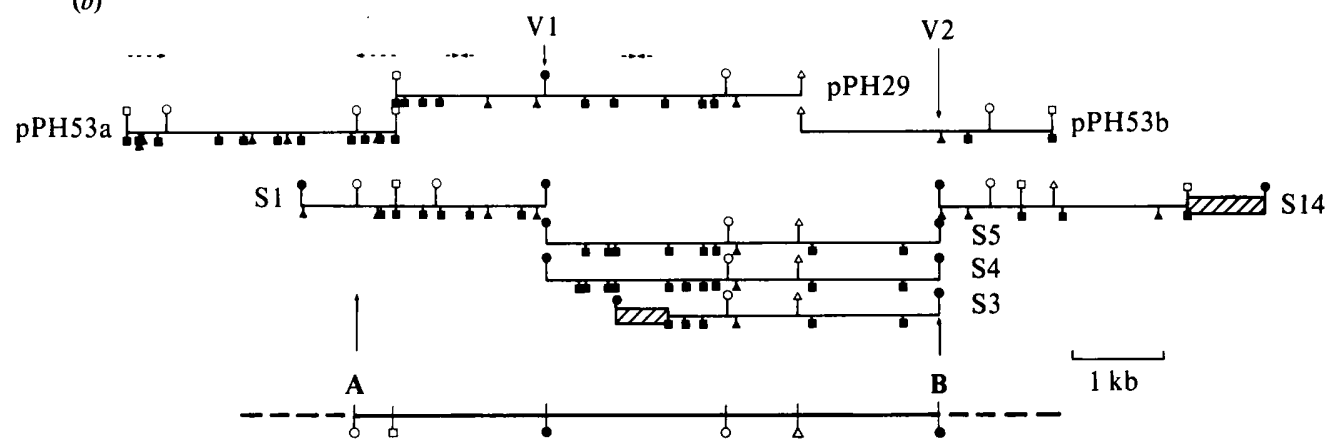

Fig. 3. Restriction mapping of PL-5 and PL-15 subcloned DNA fragments. (a) Restriction maps of PL5 and PL- 15 showing the HpaII-restriction fragments subcloned into the ClaI restriction site of pBR322, and a schematic representation of the arrangement of the major repetitive elements in PL-5 and PL-15, indicated by the letters $A, B, C$ and $D$. This was deduced from the restriction analysis summarized in $(b)$ and in the text. The right $(\mathrm{R})$ and left $(\mathrm{L})$ arms of the $\lambda-1059$ cloning vector are shown as hatched areas. Restriction sites are indicated by symbols that are defined in $(b)$.

(b) Detailed restriction maps of the subcloned HpaII restriction fragments of PL-5 and PL-15. The maps are aligned to show regions of similarity with each other and with the pPH29, pPH53a and pPH53b probe sequences. Only insert DNA segments are shown in all cases. The data described in the text suggest that the repeated element is defined by a $\sim 6.3 \mathrm{~kb}$ segment with internal restriction cuts at an EcoRI site (A) and a HpaII site (B). V1 and V2 denote the positions HpaII (MspI) restriction sites which are absent in some copies of the repeated element (see text for details). Horizontal dotted arrows indicate the positions of inverted repeat elements (foldback sequences) in pPH29 and pPH53a (Peoples et al., 1983). A simplified summary map is included to indicate the positions of internal BamHI, EcoRI, HindIII and HpaII (MspI) restriction sites which define the structure of the repeated element; the broken line indicates undefined segments bordering the repeat. Restriction sites are indicated by

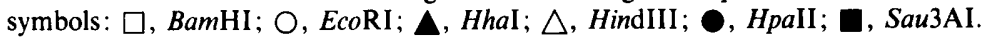

similar in structure to those in genomic DNA. Some differences were observed, and these were investigated further by the subcloning and restriction mapping of two clones, PL-5 and PL-15. The results are summarized in Fig. 3.

The maps of the entire cloned Physarum DNA segments in PL-5 and PL-15 are shown in Fig. $3(a)$, and more detailed restriction data are presented for plasmid-derived subclones in Fig. 3(b), together with maps of the pPH29, pH53a and pPH53b probes (Peoples et al., 1983) for comparison. Analysis of the data shows that PL-15 probably contains an incomplete copy of a long repeated element, $>5.8 \mathrm{~kb}$, which comprises a $4.3 \mathrm{~kb}$ BamHI/HindIII segment corresponding to the pPH29 element, a contiguous HindIII/HpaII (MspI) $1.5 \mathrm{~kb}$ segment which

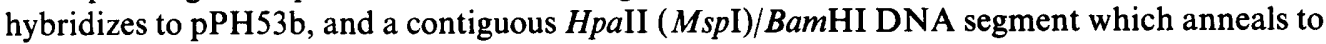
pPH53a (Fig. 3b). One HpaII-fragment subclone of PL-15, S3, has a similar structure and hybridization properties to the PL-15 subclone S4, indicating that PL-15 contains two, incomplete tandem head-to-tail copies of the same long repeated sequence, as indicated diagrammatically in Fig. 3(a). The incomplete copies of the repeats in PL-5 and PL-15 are joined to vector arms at the predicted positions of Sau $3 \mathrm{AI}$ restriction sites; this is expected since 
(a)

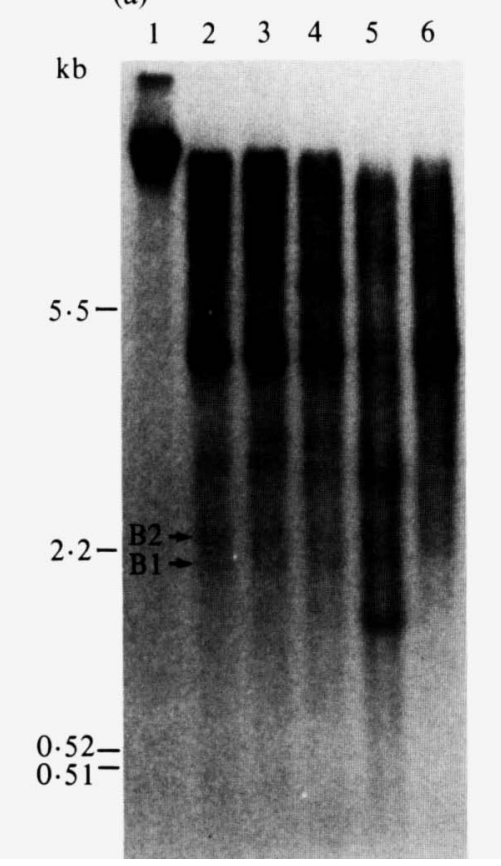

(b)

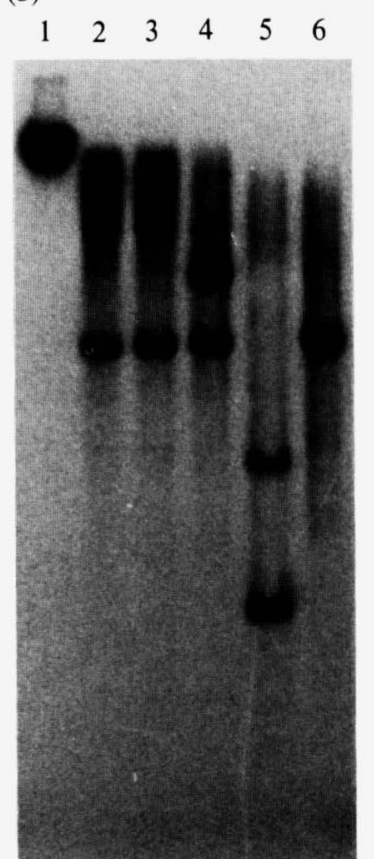

(c)

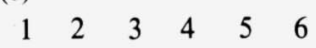

Fig. 4. Hybridization of PL-5 DNA probes to restriction digests of Physarum genomic DNA. Samples (1 $\mu \mathrm{g}$ ) of Physarum nuclear DNA were digested with (1) HpaII, (2) MspI, (3) HpaII/MspI, (4) BamHI/MspI, (5) HindIII/MspI, or (6) BamHI/HindIII, and separated on $1 \%$ agarose gels. Replicate filters were probed using: (a) total Physarum DNA, (b) PL-5/S5 subclone DNA, or (c) a $7 \mathrm{~kb} \mathrm{HpaII}$ fragment isolated from PL-5. Probes had a specific activity of $0.8 \times 10^{8}-10^{8}$ c.p.m. ( $\mu$ g DNA) ${ }^{-1}$. Autoradiographs were exposed overnight at $-50^{\circ} \mathrm{C}$. The arrows labelled $\mathrm{B} 1$ and $\mathrm{B} 2$ in $(a)$ point to faint hybridization bands of similar size to those detected by cloned Physarum DNA segments PL-5, PL-13 and PL-16 (see text and Fig. 1).

the clones are derived from a collection of partial Sau3AI-digested fragments of Physarum genomic DNA. By inspection of the restriction maps of these cloned sequences it can be concluded that the variation in hybridization properties of the different cloned copies of the HpaII-repeat in PL-15 and PL-5 (Fig. 2) can probably be explained by addition or deletion of internal Sau3AI restriction sites in repeated elements of uniform length. The absence of part of the repeat at the junction between the two tandem copies of the sequence in PL-15 in a region showing homology with pPH53a (Fig. 3) accounts for the lack of the small, pPH53-hybridizing Sau3AI restriction fragments in this clone.

\section{Characterization of additional repeated sequences in $P L-5$}

Highly repetitive sequences in Physarum DNA would be expected to generate the most prominent hybridization signals with a nick-translated, high-complexity total DNA probe (Wensink et al., 1979; Peoples et al., 1983). Fig. 4(a) shows the result obtained when various restriction digests of Physarum genomic DNA were hybridized to total Physarum DNA. The probe can be seen to hybridize to $\mathrm{M}^{+}$DNA segments in HpaII digested DNA (lane 1). These sequences are cleaved by $M s p I$ generating a heterogeneous collection of DNA fragments and a single, predominant $4 \cdot 3 \mathrm{~kb}$ DNA band (lanes 2 and 3). These major bands of hybridization correspond to the highly abundant $H p a$ II-repeat sequence, since a nearly identical result was obtained using a HpaII-repeat subclone (PL-5/S5) as probe (Fig. $4 b$ ), except that in this case the background hybridization signals in each track were considerably reduced. The hybridization properties of this probe can be predicted from the known restriction properties of the cloned PL5/S5 sequence. No major bands of hybridization were detected using a total Physarum DNA 
probe except those associated with the HpaII-repeat sequence. It is concluded that HpaIIrepeats are probably the only major family of long, highly repetitive elements in the Physarum genome.

High-molecular-weight fragments in $M s p$ I digests showing homology with PL-5/S5 (Fig. $4 b$, lanes 2 and 3) were digested by BamHI, generating a predominant hybridization signal to fragments $5.8 \mathrm{~kb}$ long (lane 4 ). This almost certainly arises due to cleavage of additional HpaIIrepeats which have lost an internal $M s p \mathrm{I} / \mathrm{HpaII}$ restriction site (V1 variable site, Fig. $3 b$ ). A similar conclusion was reached previously on examining the properties of the pPH53b sequence (V2 variable site, Fig. $3 b$ ) (see Peoples \& Hardman, 1983). As shown below, variation in the position of $M s p I / H p a I I$ sites may also occur within the additional repeated element located in the PL-5 sequence.

The $\sim 7 \mathrm{~kb} \mathrm{HpaII}$ restriction fragment of PL-5 was isolated from agarose gels, nick-translated and used as a probe to a Southern blot filter of Physarum genomic DNA similar to those shown in Fig. $4(a, b)$. The results (Fig. $4 c$ ) show that this fragment contains sequences belonging to the $2.7 \mathrm{~kb} H$ indIII/MspI segment of the HpaII-repeat, and the repeated element responsible for the $2.0 \mathrm{~kb}$ hybridization band detected in $M s p$ I digests of genomic DNA using a PL-5 probe (Fig. $1 b$ ). This result confirms that the $2.0 \mathrm{~kb}$ band originates from an additional repetitive element in the $7 \mathrm{~kb} \mathrm{HpaII} \mathrm{(MspI)} \mathrm{fragment} \mathrm{of} \mathrm{PL-5} \mathrm{which} \mathrm{is} \mathrm{distinct} \mathrm{from} \mathrm{the} \mathrm{HpaII-repeat,} \mathrm{and} \mathrm{that} \mathrm{this}$ cloned repeated element has a different distribution of surrounding $M s p I$ sites from the majority of the genomic copies of the sequence. As in the case of the HpaII-repeats, this probably resulted from deletion of a HpaII (MspI) restriction site. Close inspection of Fig. 4(a) shows that a faint hybridization signal corresponding to the position of these repeated elements is generated using a total Physarum DNA probe (B1, Fig. $4 a$ ). Likewise a signal of similar intensity can be seen at $2.2 \mathrm{~kb}$ (B2, Fig. $4 a$ ), at a position expected for the additional repetitive element located in PL-16 (Fig. 1). The results are in accord with the hypothesis that these additional repeated elements are less abundant than the HpaII-repeats with which they are associated in $\mathbf{M}^{+}$DNA.

\section{DISCUSSION}

Although previous work in this laboratory has led to the identification of a HpaII-resistant compartment in Physarum DNA we had not presented evidence that $\mathbf{M}^{+}$DNA is enriched in 5meC. In the present study we demonstrate that the HpaII-resistant, $\mathbf{M}^{+}$fraction of the Physarum genome is indeed hypermethylated; it is enriched approximately fivefold in 5-meC compared with $\mathrm{M}^{-}$sequences. No 6-methyladenine was detected, in accord with previous observations using different methods of analysis (Evans et al., 1973). Evidence is presented that 5-meC is located in $\mathrm{CpG}$ doublets of $\mathrm{HpaII}$ and HhaI restriction sites in $\mathrm{M}^{+}$DNA, but many additional sites of methylation are required to account for the observed levels of 5-meC. Nearest neighbour analysis of total Physarum DNA gives a CpG doublet frequency of $2 \mathrm{~mol} \%$ (Whittaker, 1982). HPLC analysis shows that the $\mathrm{M}^{+}$DNA fraction contains $4 \cdot 16 \mathrm{~mol} \% 5-\mathrm{meC}$. If $\mathrm{CpG}$ doublets were equally frequent in $\mathbf{M}^{+}$and $\mathrm{M}^{-}$DNA then only half of the 5-meC in the $\mathbf{M}^{+}$fraction can be accommodated in $\mathrm{CpG}$ sequences. This figure is even less if $\mathrm{CpG}$ doublets occur less frequently in $\mathrm{M}^{+} \mathrm{DNA}$, as indicated by the lack of $M s p \mathrm{I}$ and $H h a \mathrm{I}$ restriction sites in cloned DNA from these regions (see below). It is therefore likely that $5-\mathrm{meC}$ residues may be present in sequences other than $\mathrm{CpG}$. In plants, where as much as $30 \%$ of the cytosine residues may be methylated (Shapiro, 1976), 5-meC occurs in $\mathrm{CpA}, \mathrm{CpC}$ and $\mathrm{CpT}$ as well as $\mathrm{CpG}$, in sequences with the general formula $\mathrm{CpXpG}$ (Gruenbaum et al., 1981). Additional sites of methylation such as these conceivably could affect restriction of $\mathrm{M}^{+}$DNA sequences by enzymes other than HpaII or HhaI.

$M s p I$ restriction sites occur much less frequently in hypermethylated, $\mathrm{M}^{+}$segments of Physarum DNA than in the remainder of the genome (Whittaker \& Hardman, 1980; Whittaker et al., 1981). This observation is consistent with the suggestion that methylated sequences may be subject to an enhanced rate of mutation (Bird, 1980), since these restriction sites are preferentially methylated in $\mathrm{M}^{+}$DNA. Point mutations in the recognition sequence would lead to elimination of the restriction site, and evidence presented here indicates that such changes 
have occurred at $M s p I$ restriction sites in the HpaII-repeats which dominate this DNA compartment, and possibly also in other less highly repeated elements in $\mathbf{M}^{+}$DNA, such as the ' $2.0 \mathrm{~kb}$ ' repeats in PL-5.

A head-to-tail tandem duplication of the HpaII-repeat occurs in PL-15 (Fig. 3). Similar organizations in genomic DNA may account for the faint high-molecular-weight bands in $M s p \mathrm{I}$ restriction digests (Fig. 1 and Fig. $4 b$ ) probed with these sequences. The $2.7 \mathrm{~kb} H$ indIII $/ M s p \mathrm{I}$ segment of the HpalI-repeat is similarly duplicated in the PL-5/S5 subclone (Fig. $4 b$ ) and the $7 \mathrm{~kb} \mathrm{HpaII} \mathrm{fragment} \mathrm{(Fig.} \mathrm{4c)} \mathrm{of} \mathrm{PL-5.} \mathrm{Previous} \mathrm{studies} \mathrm{of} \mathrm{pPH53a} \mathrm{show} \mathrm{that} \mathrm{it} \mathrm{contains} \mathrm{a} \mathrm{head-}$ to-head tandem repeat of the BamHI/EcoRI portion of the HpaII-repeat (Fig. 3b) (Peoples et al., 1983). This indicates that local repetition of $\mathrm{HpaII-repeats} \mathrm{may} \mathrm{be} \mathrm{a} \mathrm{general} \mathrm{feature} \mathrm{of} \mathrm{M}^{+}$DNA segments. These properties raise additional questions regarding the nature of the sequences at the termini of HpaII-repeats, which are currently being investigated.

Some interesting comparisons can be made between the properties of the long, abundant HpaII-repeat in Physarum DNA and similar repeated elements in other eukaryotic organisms. HpaII-repeats have a similar length, methylation properties and repetition frequency (Peoples \& Hardman, 1983) to the KpnI elements in primate DNA (Maio et al., 1981 ; Grimaldi \& Singer, 1982) and the MIF-BamHI elements in mouse DNA (Meunier-Rotival et al., 1982; Fanning, 1983). Recent studies have revealed extensive and significant sequence homology between these long, repetitive elements in mouse and primate genomes (Singer et al., 1983) indicating that they have a common origin. Their relatedness to the HpaII-repeated element in Physarum DNA is not known, but is currently being investigated in this laboratory. Other similarities include the observation that segments of HpaII-repeats (Peoples \& Hardman, 1983) and KpnI-repeats (Lerman et al., 1983) may be scrambled in some DNA segments, possibly similar to highly repetitive sequences in chicken and Drosophila DNA (Musti et al., 1981; Wensink et al., 1979).

Apart from the HpaII-repeats which dominate the methylated compartment of Physarum DNA, the present study provides evidence for the presence of other distinct, less highly repeated sequences in some segments of $\mathbf{M}^{+}$DNA. These additional sequences have yet to be characterized. Additionally, it remains to be determined why the regions of the genome containing clusters of these specific repetitive elements are preferentially methylated, and whether their role in eukaryotic DNA is largely structural or related to gene function.

The authors are grateful to the Science \& Engineering Research Council and Medical Research Council for supporting this work, and for the award of an MRC Research Studentship to D.P. We are also indebted to Mairi Gordon for excellent technical assistance and Professor H. M. Keir for provision of research facilities.

\section{REFERENCES}

BAYEN, M. \& Dalmon, J. (1976). 5-Methylcytosine in Chlorella pyrenoidosa DNAs. Biochimica et biophysica acta 432, 273-280.

Benton, W. D. \& Davis, R. W. (1977). Screening of $\lambda$-gt recombinant clones by hybridization to single plaques in situ. Science 196, 180-182.

BIRD, A. P. (1980). DNA methylation and the frequency of $\mathrm{CpG}$ in animal DNA. Nucleic Acids Research 8, 1499-1504.

Bird, A. P., Taggart, M. H. \& SMith, B. A. (1979). Methylated and unmethylated DNA compartments in the sea urchin genome. Cell 17, 889-901.

COOKE, D. J. \& DEE, J. (1975). Methods for the isolation and analysis of plasmodial mutants in Physarum polycephalum. Genetical Research 24, 175188.

Evans, H. H., Evans, T. E. \& Littman, S. (1973). Methylation of parental and progeny DNA strands. Journal of Molecular Biology 74, 563-577.

FANNING, T. G. (1983). Size and structure of the highlyrepetitive Bam HI element in mice. Nucleic Acids Research 11, 5073-5091.
Grimaldi, G. \& Singer, M. F. (1982). A monkey Alu sequence is flanked by 13-base pair direct repeats of an interrupted $\alpha$-satellite DNA sequence. Proceedings of the National Academy of Sciences of the United States of America 79, 1497-1500.

Gruenbaum, Y., Naveh-Many, T., Cedar, H. \& RAZIN, A. (1981). Sequence specificity of methylation in higher plant DNA. Nature London 292, 860 862.

Hardman, N., Jack, P. L., Brown, A. J. P. \& MCLACHLAN, A. (1979). Distribution of inverted repeat sequences in nuclear DNA from Physarum polycephalum. European Journal of Biochemistry 94, 179-187.

Hattman, S., Keister, T. \& Gottehrer, A. (1978). Sequence specificity of DNA methylases from Bacillus amyloliquefaciens and Bacillus brevis. Journal of Molecular Biology 124, 701-711.

Lerman, M. I., Thayer, R. E. \& Singer, M. F. (1983). KpnI family of long interspersed repeated DNA sequences in primates: polymorphism of family members and evidence for transcription. Proceedings 
of the National Academy of Sciences of the United States of America 80, 3966-3970.

McLachlan, A. \& Hardman, N. (1982). Analysis of foldback sequences and repetitive sequences in cloned segments of nuclear DNA from Physarum polycephalum. Biochimica et biophysica acta 697, 89-100.

Maio, J. J., Brown, F. L., McKenna, G. W. \& MUsich, P. R. (1981). Highly-repetitive component $\alpha$ and related alphoid DNA in man and monkeys. Chromosoma 83, 127-144.

Mavilio, F., Giampaolo, A., Care, A., Migliaccio, G., Calandrini, M., Russo, G., Pagliardi, G. L., Mastroberardino, G., Marinucci, M. \& Peschle, C. (1983). Molecular mechanisms of human haemoglobin switchings: selective undermethylation and expression of globin genes in embryonic, foetal and adult erythroblasts. Proceedings of the National Academy of Sciences of the United States of America 80, 6907-6911.

Meunier-Rotival, M., Soriano, P., Cuny, G., Strauss, F. \& Bernardi, G. (1982). Sequence organization and genomic distribution of the major family of interspersed repeats of mouse DNA. Proceedings of the National Academy of Sciences of the United States of America 79, 355-359.

Musti, A. M., Sobieski, D. A., Chen, B. B. \& EdEN, F. C. (1981). Repeated deoxyribonucleic acid clusters in the chicken genome contain homologous sequence elements in scrambled order. Biochemistry 20, 2989-2999.

Peoples, O. P. \& Hardman, N. (1983). An abundant family of methylated repetitive sequences dominates the genome of Physarum polycephalum. Nucleic Acids Research 11, 7777-7788.

Peoples, O. P., Robinson, A. C., Whittaker, P. A. \& HaRdMaN, N. (1983). Sequence organisation in nuclear DNA from Physarum polycephalum: genomic organisation of DNA segments containing foldback sequences. Biochimica et biophysica acta 741, 204-213.

ShaPIRo, H. S. (1976). Distribution of purines and pyrimidines in deoxyribonucleic acid. In Handbook of Biochemistry and Molecular Biology, vol. II, pp. 241-311. Edited by G. D. Fasman. Cleveland, USA : CRC Press.

Singer, M. F., Thayer, R. E., Grimaldi, G., Lerman, M. I. \& FANNING, T. G. (1983). Homology between the KpnI primate and BamHI (MIF-1) rodent families of long interspersed repeated sequences. Nucleic Acids Research 11, 5739-5745.

Smith, G. E. \& Summers, M. D. (1980). The bidirectional transfer of DNA and RNA to nitro cellulose or diazobenzyloxymethyl-paper. Analytical Biochemistry 109, 123-129.

Southern, E. M. (1975). Detection of specific sequences among DNA fragments separated by gel electrophoresis. Journal of Molecular Biology 98, 503-517.

Wensink, P. C., Tabata, S. \& Pachl, C. (1979). The clustered and scrambled arrangement of moderatelyrepetitive elements in Drosophila DNA. Cell 18, 1231-1246.

WhITTAKER, P. A. (1982). Methylation of nuclear DNA in Physarum polycephalum. PhD. thesis, University of Aberdeen, UK.

Whittaker, P. A. \& Hardman, N. (1980). Methylation of nuclear DNA in Physarum polycephalum. Biochemical Journal 191, 859-862.

Whittaker, P. A., Mclachlan, A. \& Hardman, N. (1981). Sequence organisation in nuclear DNA from Physarum polycephalum: methylation of repetitive sequences. Nucleic Acids Research 9, 801-814. 